\title{
Elevación localizada del seno maxilar a través de un abordaje transalveolar
}

\author{
KREKELER, G.* \\ SPIELBERG, M.* \\ SOEJIMA, Y.**
}

Elevación localizada del seno maxilar a través de un abordaje transalveolar. Av Odontoestomatol. 2001; 13, 1: 49-55

\section{INTRODUCCIÓN}

A pesar de las numerosas innovaciones desarrolladas en los últimos años en materia de implantología, sigue siendo el déficit de un terreno óseo adecuado para la inserción de raíces artificiales, una de las causas más importantes por las cuales se ve dificultada la inserción de implantes dentales. Un ejemplo clásico puede observarse en el maxilar superior, sector posterior debido a que los molares superiores forman parte del grupo de piezas dentarias que con mayor frecuencia primero se pierden. El patrón de reabsorción "postextraccionem" que se observa en esta región anatómica, no solamente ocurre desde el reborde alveolar remanente, sino que por el contrario ocurre principalmente la neumatización del seno maxilar, lo que genera el adelgazamiento del suelo del antro desde coronal hacia caudal (Solar et al. 1998). Esta limitación anatómica fue reconocida tempranamente y generó diversas alternativas como ser: la implantación en el sector lateral de la maxila sólo hasta donde el terreno lo permita, en combinacion con una rehabilitación a extensión distal, la implantación en la región de la tuberosidad (Benzing et al. 1996), o bien el elevamiento de la membrana sinusal (Sinuslift). Mediante la aplicación de este último recurso se puede lograr un adecuado lecho implantario, con óptimos resultados a largo plazo (ten Bruggenkate et al. 1992, van den Bergh et al. 1998).

\section{ELEVACIÓN DEL SENO MAXILAR (SINUSLIFT)}

H.Tatum (1977) fue uno de los primeros autores en describir una alternativa quirúrgica para corregir una deficiencia de hueso en el maxilar superior, sector posterior. Este autor describió una técnica, con la cual logra el elevamiento del seno maxilar a través de un abordaje transalveolar. A partir de entonces se describieron diversas modificaciones como ser por ejemplo, el abordaje, el material de relleno (hueso autólogo, sustitutos óseos), la transplantación e implantación en uno o dos tiempos quirúrgicos, etc (Boyne y James 1980, Smiler y Holmes 1985, Kent y Block 1989, Hirsch y Erikson 1991, Catone et al. 1992, Small et al. 1993, Betts y Miloro 1994, Haas et al. 1998, Jensen et al. 1998).

A pesar de las numerosas innovaciones referentes a sustitutos óseos, sigue siendo hasta el día de hoy, el uso de hueso autólogo, el material de elección (Gold standart) para la corrección de defectos alveolares.

La técnica del sinuslift se describe frecuentemente en combinación con un transplante de hueso autólogo tomado en forma de un bloque corticoesponjoso de la cresta ilíaca (Nyström et al 1993). Los resultados de este tipo de intervención muestran una gran reabsorción del volumen del tejido óseo transplantado, quedando solamente una lámina delgada de hueso sobre la porcion apical de los implantes, la cual absorve las cargas funcionales. Estas observaciones nos llevaron a distanciarnos ligeramente de la técnica clasica recientemente mencionada. De modo tal que en situaciones con defectos óseos localizados preferimos abordar una técnica más conservadora, cubriendo solamente la porción enosal de los implantes emergentes en el seno maxilar, a la manera de un sinuslift fisiológico, con partículas de hueso esponjoso tomado de las clásicas zonas dadoras intraorales, como son por ejemplo la región del mentón o la zona retromolar - para solventar defectos que requieren menor volumen óseo - o bien de las zonas dadoras extraorales, como son la cresta ilíaca o la cabeza de la tibia, solamente para solventar defectos que requieren un mayor volumen óseo. Los resultados a largo plazo muestran clínicamente implantes dentales firmes,

* Klinik für Zahn-, Mund und Kieferheilkunde der Universität Freiburg, Abteilung Poliklinik für Zahnerhaltungskunde, sektion Parodontologie, Hugstetterst. 55, 79106 Freiburg, Alemania.

** Soejima Dental Clinic Kumamoto, Japan. 
capaces de absorber las cargas funcionales de la oclusión. Radiográficamente se observa, que la porción apical de los implantes permanece cubierta por una lámina de tejido óseo, a la manera de pequeñas cúpulas, en analogía a lo observado en la dentición natural (Krekeler et al 1998, Spielberg 1999).

En los casos en los cuales el remanente óseo local es muy delgado y la estabilidad primaria inicial del implante no está garantizada, pero a pesar de ello se pretende aumentar el volumen óseo y llevar a cabo la implantación en un solo tiempo quirúrgico, se hace indispensable la utilización de un bloque de hueso corticoesponjoso, el cual se fija con los implantes a la manera de tornillos de osteosíntesis. Si la corrección del defecto óseo y la implantación se llevan a cabo en dos tiempos quirúrgicos independientes, es recomendable esperar entre 6 y 9 meses hasta el momento de la implantación, permitiendo así la remodelación e integración del transplante (Jensen y Greer 1992, ten Bruggenkate et al. 1998).

\section{ELEVACIÓN LOCAL DEL SENO MAXILAR A TRAVÉS DE UN ABORDAJE TRANSALVEOLAR}

Los casos que presentan defectos menores y la estabilidad primaria inicial del implante está garantizada, basta con cubrir solamente la porción enosal del implante emergente en la cavidad del seno maxilar con hueso autólogo. No siempre es indispensable un gran abordaje a través de la pared lateral del hueso maxilar superior a la manera de una ventana, llenando en forma masiva el seno maxilar, así como tampoco vemos la necesidad de recurrir en forma rutinaria a las zonas dadoras extraorales.

Por lo general es posible llevar a cabo un aumento óseo localizado con partículas de hueso autólogo que se obtienen durante una conformación del lecho implantario. A través del lecho implantario se eleva localmente la membrana de Schneider, se inserta localmente el hueso ganado y a continuación se enrosca el implante de modo que la porción enosal del mismo, quede cubierto por hueso.

\section{TÉCNICA QUIRÚRGICA}

Para la conformación del lecho implantario se recomienda en primer lugar el uso de una fresa cilíndrica hueca. En nuestro caso en particular utilizamos una fresa cilíndrica hueca del sistema ITI, con la cual

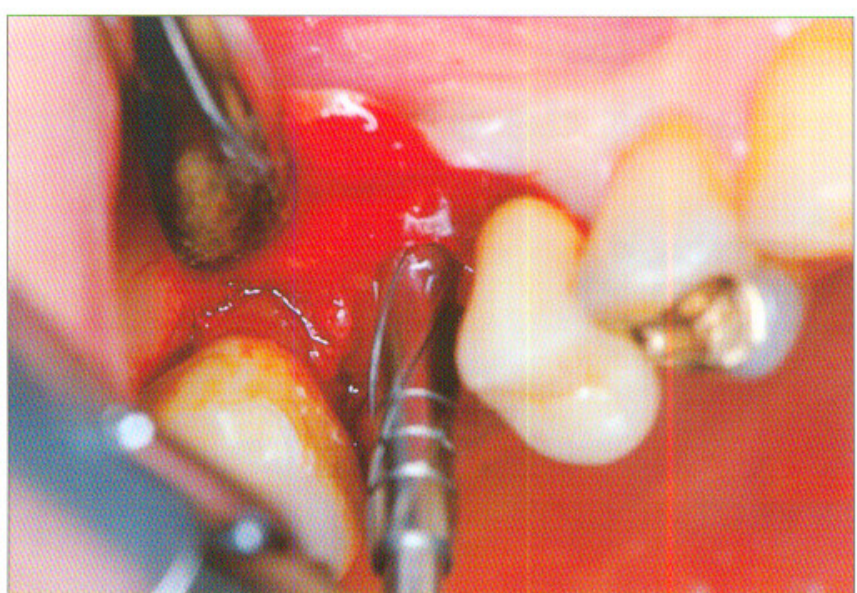

Fig. la.: Conformación del lecho implantario mediante una fresa cilíndrica hueca del sistema ITI.

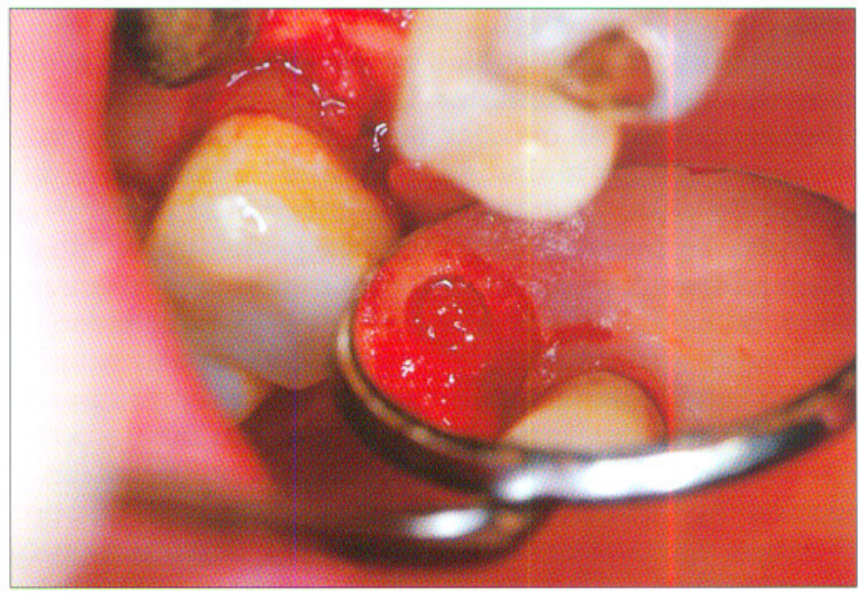

Fig. 1b.: Cilindro óseo in situ.

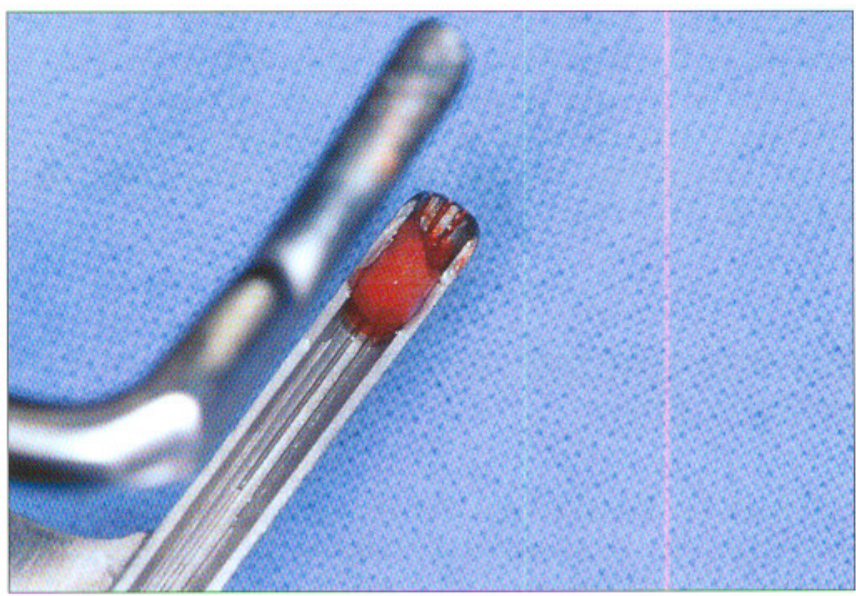

Fig. 2.: Toma del cilindro óseo con una pinza especialmente diseñada para tal finalidad (Ahlskog, Fa., Tuttlinge Germany).

se puede preparar cuidadosamente el lecho implantario hasta la cortical del seno maxilar (Foto $1 \mathrm{a}, \mathrm{b}$ ). Mediante una pinza especialmente confeccionada 


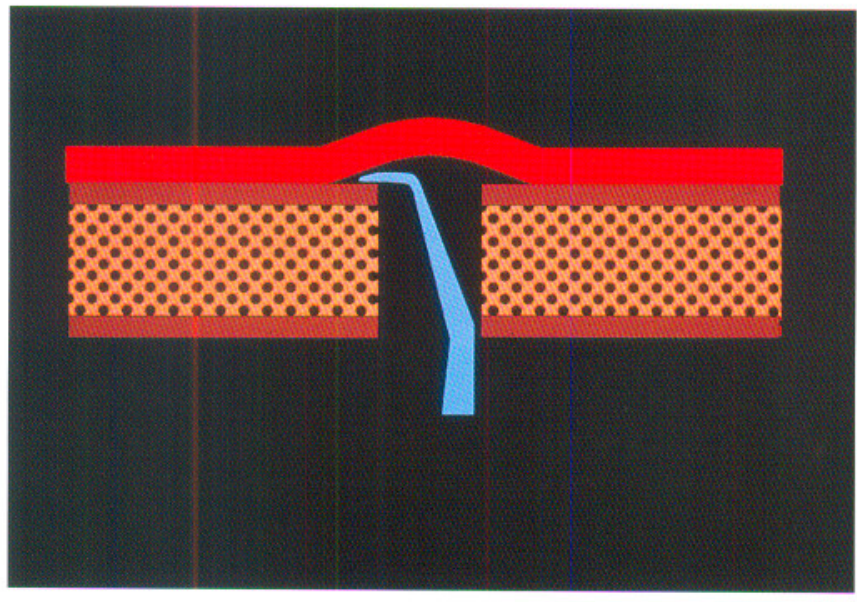

Fig. 3a.: Esquema del elevamiento localizado de la membrana sinusal.

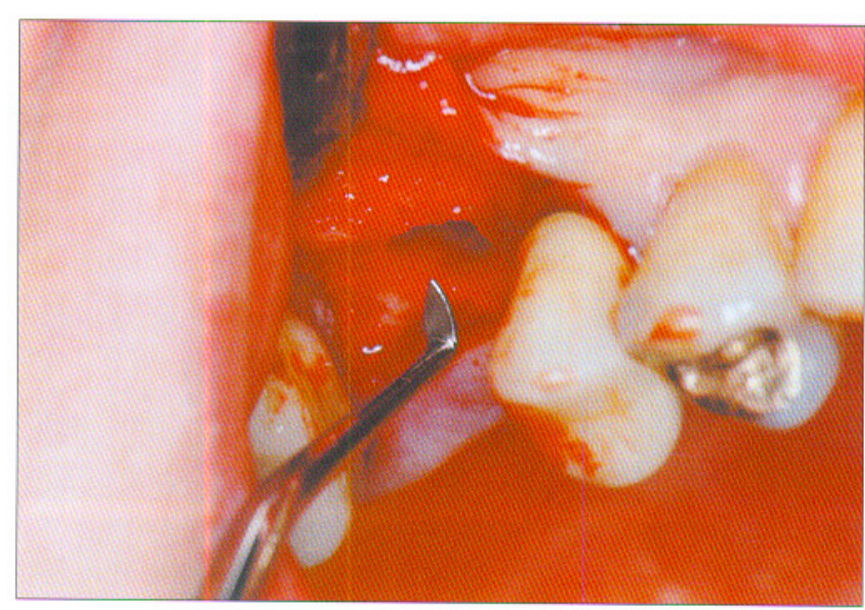

Fig. 3b.: Pequeño elevador con el cual se realiza el levantamiento de la membrana sinusal a través del lecho implantario.

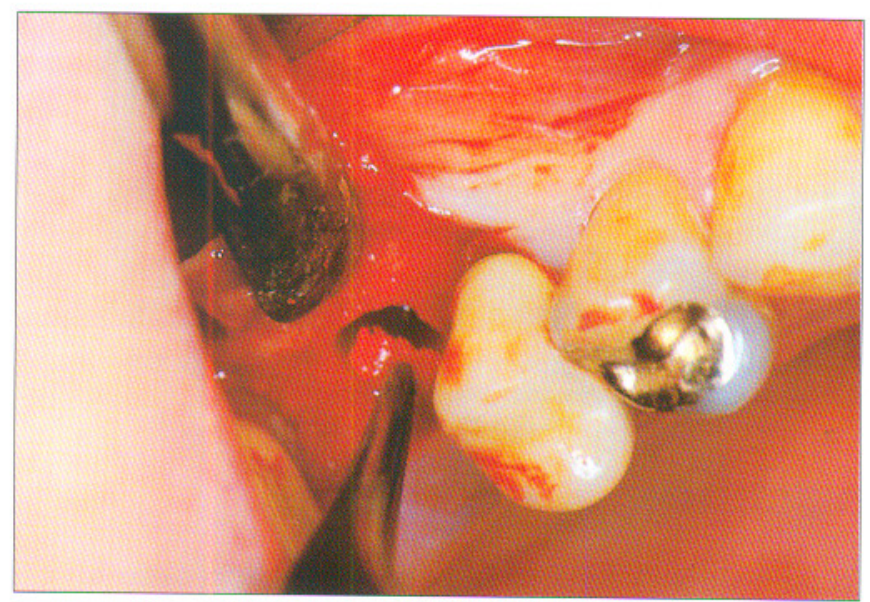

Fig. 4a.: El cilindro de hueso autólogo obtenido durante la conformación del lecho implantario debe ser triturado con una pinza para hueso (pinza de Luer), para luego ser introducido en el seno del maxilar elevado, en forma de partículas de hueso vital.

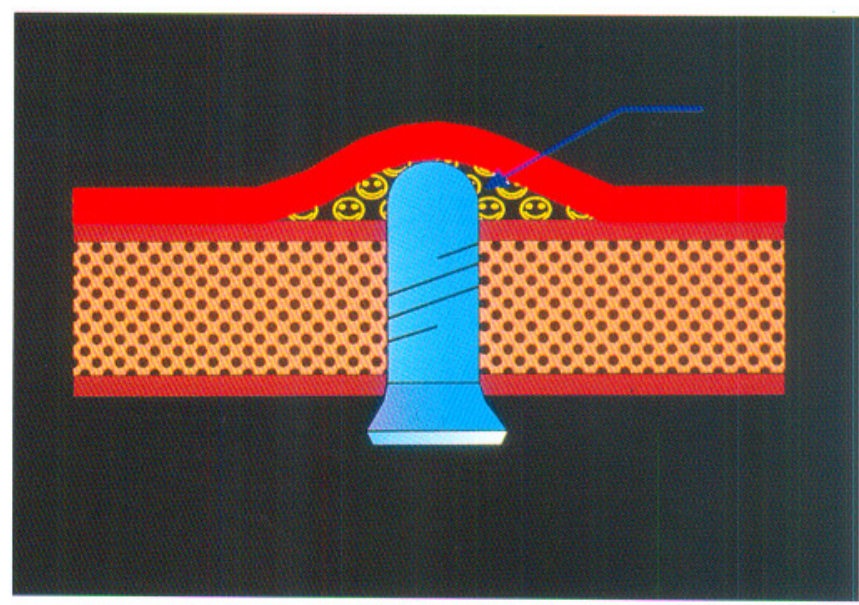

Fig. 4b.: Esquema del sinuslift localizado.

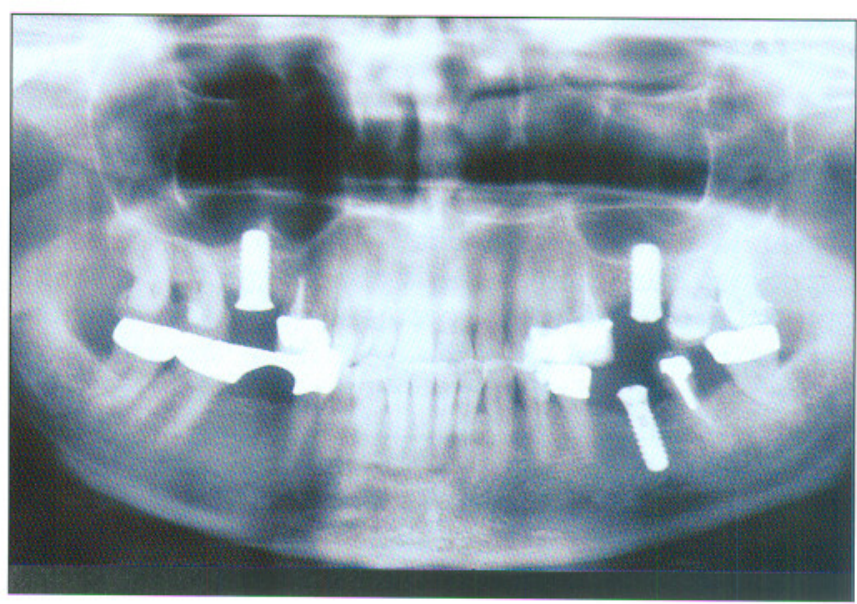

Fig. 4c.: Rx Panorámica inmediatamente post-intervención. En la parte apical derecha del implante se oberva la pequeña porción de hueso que conformaba el suelo óseo del seno maxilar. En la porción apical izquierda se reconoce el hueso esponjoso particulado elevado a través del lecho implantario.

para la toma del cilindro óseo (Ahlskog, Fa. Tuttlingen), es posible retirar casi la totalidad del material quedando solamente la delgada lámina de hueso cortical (Foto 2). El manejo adecuado del tejido óseo fuera del organismo hasta el momento de la transplantación es de fundamental importancia. La toma debe conservarse en un medio con sangre del propio paciente y no debe ser escurrida con abundante solución fisiológica, con lo cual se perdería en gran parte el potencial oseoinductivo propio del hueso autólogo. El hueso cortical remanente, que forma el suelo del seno maxilar se eleva meticulosamente hacia coronal, en nuestro caso en particular, a diferencia de lo que se describe en la técnica convencional con osteotomos con punta activa (Summers 1994), mediante un instrumento cilíndrico de punta inactiva. Durante esta maniobra debe prestarse especial atención de no perforar la membrana sinusal. 


\section{AVANCES}

Volumen 13 - $\mathrm{N}^{\circ} 1$ - Abril 2001

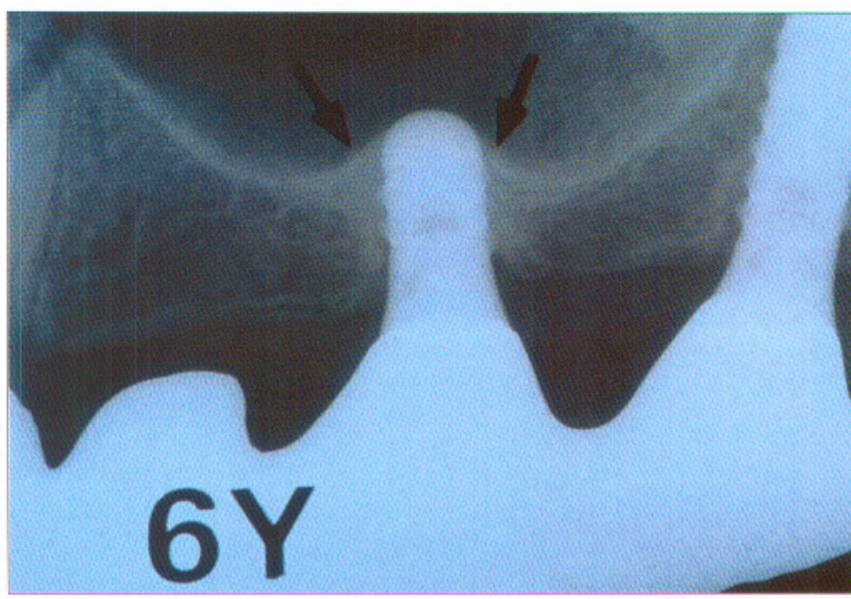

Fig. 5.: Rx 6 años post-intervencióin. Se observa claramente que todo el tejido óseo que no fue sometido a cargas funcionales sufrió un pro ceso de reabsorción.

Mediante un pequeño periostótomo con extremos acodados, pero que a su vez todavía permite ser introducido a través del lecho implantario, se procede a elevar la membrana sinusal (Foto 3a, b ). El hueso esponjoso ganado durante la conformación del lecho implantario debe ser ligeramente triturado con una pequeña pinza. A continuación debe insertarse el implante dental. Los implantes macizos roscados del sistema ITI se prestan adecuadamente para esta técnica, ya que poseen un extremo redondeado, el cual brinda un soporte adecuado para la membrana sinusal y las partículas de hueso transplantadas (Foto $4 a, b, c)$. El hueso puede ser estabilizado en forma adicional con un adhesivo a base de fibrina. Se recomienda la prescripción de una cobertura antibiótica postoperatoria.

\section{EXPERIENCIA CLÍNICA}

Esta tecnica quirúrgico se lleva a cabo en la Clínica Universitaria de Freiburg desde hace más de seis años. Tanto los resultados clínicos como los controles radiográficos muestran una situación con muy buen pronóstico, con tendencia a permanecer estable a lo largo de los años. La foto número 5 muestra radiográficamente la situación seis años post-transplantación. Se puede observar la porción apical del implante cubierta por una delgada lámina de tejido óseo. Las fotos $6 \mathrm{a}, \mathrm{b}$ y c muestran controles radiográficos tomados, al año, a los dos y tres años respectivamente. En todas las imágenes radiográficas se observa una adecuada densidad ósea que circunda a los implantes dentales. Estas imágenes muestran una situación estable a lo largo del tiempo (steady- state)
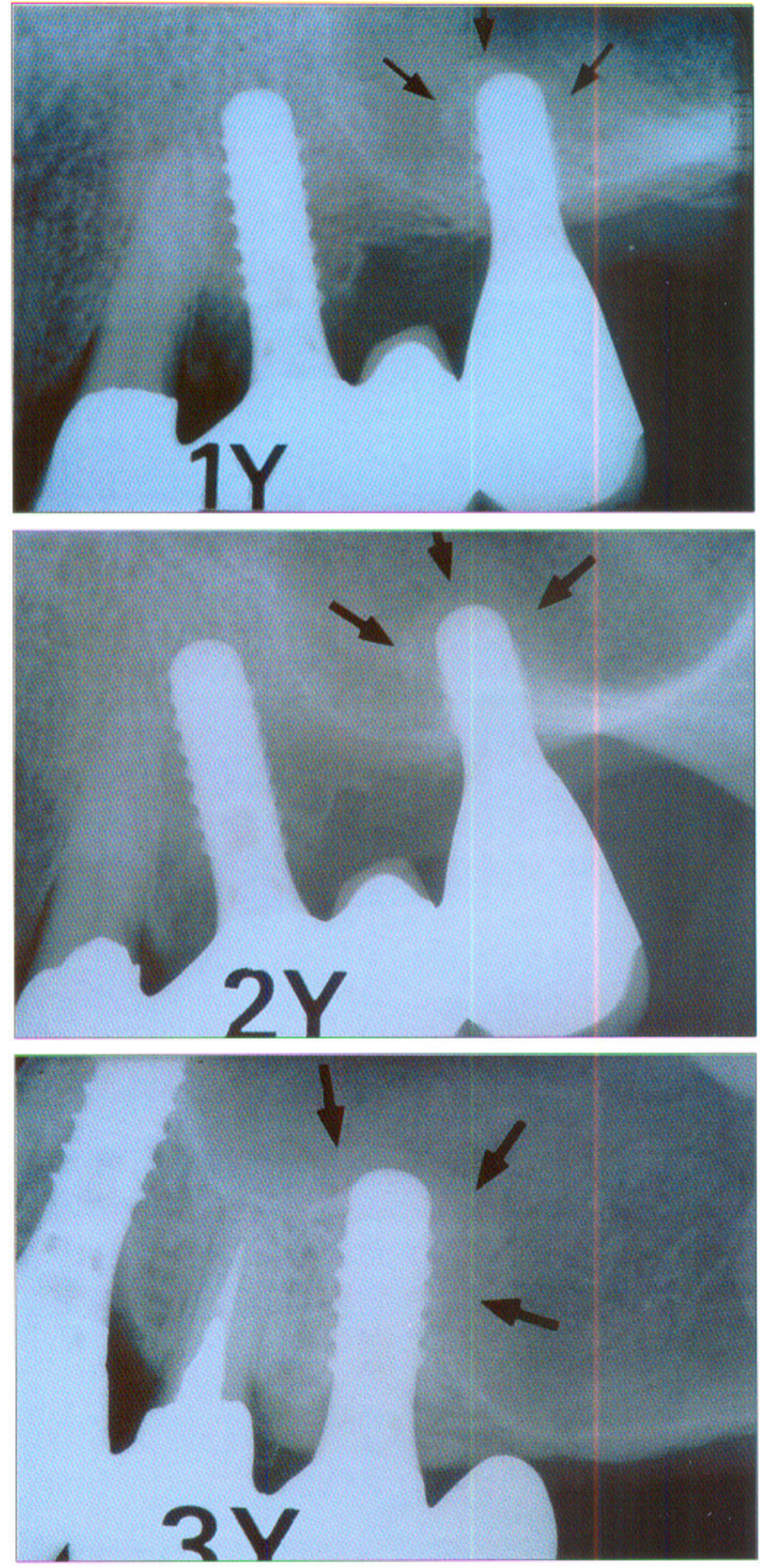

Fig. 6.a-b-c.: Las radiografías periapicales muestran la situación al año, a los dos años $y$ tres años post-intervención.

\section{DISCUSIÓN}

La falta de una adecuada oferta de tejido óseo en el sector posterior de la maxila, constituye una de las limitaciones más frecuentes para la inserción de implantes dentales. H. Tatum (1977) fue uno de los primeros autores que describió una técnica quirúrgi- 
ca con el fin de resolver esta dificultad. El autor propuso el elevamiento del seno maxilar con hueso autólogo a través de un abordaje transalveolar. Como resultado observó la oseointegración del material transplantado en el seno maxilar, de modo tal que la implantación llevada a cabo en forma diferida en un segundo tiempo quirúrgico trascendió en un lecho de hueso vital (Schweiberer 1982).

Uno de los requisitos más importantes para garantizar la oseointegración a largo plazo es un lecho implantario tanto cualitativamente así como cuantitativamente adecuado, a semejanza con la dentición natural, exceptuando las diferencias que existen entre dientes naturales e implantes.

El hueso autólogo sigue siendo hasta el día de hoy, el mejor material de elección para la corrección de defectos oseos (Goldstandart) (Basset 1972, Spiessl 1976, Boyne y James 1980, Tatum 1986, ten Bruggencate et al. 1992). Para la corrección de pequeños defectos por lo general se utilizan transplantes libres, es decir sin una directa microanastomosis entre el lecho receptor y el transplante, de tal modo que el éxito de la intervención depende en gran medida de la estructura y composición misma del hueso a transplantar, la vascularización del lecho receptor, así como del manejo adecuado de los tejidos durante la intervención misma. El pequeño porcentaje de células que sobreviven, se encuentran en los primeros días destinadas a nutrirse del lecho receptor solamente por difusión. Uno de los requisitos más importantes son, la adecuada congruencia con el lecho receptor, así como una mínima estabilidad inicial del transplante. La supervivencia de los osteoblastos transplantados también depende en gran medida del grado y velocidad con que ocurre la revascualarizacion del transplante (Berchardt 1983). La mayor parte de ellos sufre un proceso de necrosis, permaneciendo la porcion mineral del hueso, la cual funciona como una estructura guía para la nueva formación de hueso. Este fenómeno se conoce con el nombre de oseoconducción (Kübler et al. 1992). Simultáneamente se da el fenómeno conocido con el nombre de oseoinducción, por la cual se entiende la inducción ósea por acción humoral. Estas sustancias oseoinductoras son suministradas tanto por el transplante mismo, así como por el lecho receptor durante el período de remodelación y cicatrización (Urist et al. 1967). Las sustancias oseoinductoras juegan un papel fundamental dentro del contexto de la cicatrización ósea.

Si se comparan transplantes de hueso esponjoso con los de hueso cortical, los primeros poseen una mayor celularidad, lo cual podría ser una de las posibles explicaciones por las cuales estos muestran mejores resultados en cuanto a la remodelación y cicatrización ósea (Abbot et al 1947, Albrektsson 1980). La incorporación e integracion del transplante no dependen solamente de las cualidades de éste mismo, sino que también están influenciadas en gran medida por las características del lecho receptor, a partir del cual se origina todo el proceso de difusión y revascularización (Rudzski et al 1976). Otro punto importante a tener en cuenta es la distancia que existe entre las fuentes nutricias del lecho receptor y las células transplantadas, razón por la cual transplantes de dimensiones pequeñas muestran mejores resultados que transplantes de mayor volumen, en los cuales la distancia hasta el centro del transplante es mayor (Ray et al. 1963, Schweiberer 1982).

Todo las fenómenos conocidos que ocurren durante la remodelación e integración ósea también se dan en el caso de un sinuslift.

Una mínima invasión quirúrgica y un manejo adecuado de los tejidos (handling quirúrgico) conllevan a una adecuada y rápida cicatrización, así como a una oseointegración favorable de los implantes. Utilizando una fresa cilíndrica hueca normada a muy baja velocidad, es posible obtener un volumen óseo adecuado para solventar defectos menores. En situaciones, en las cuales la cantidad de material obtenido durante la conformación del lecho implantario no es suficiente, pueden abordarse adicionalmente las clásicas áreas dadoras intraorales o extraorales.

La conformación de un adecuado lecho implantario de hueso vital, así como la estabilidad primaria inicial del implante forman parte de los requisitos indispensables para la oseointegración de un implante.

Cumpliendo estrictamente con las indicaciones de un sinuslift local, ¿Puede este recurso quirúrgico, ser considerado como una alternativa adecuada para la corrección de péqueños defectos en el sector posterior del maxilar superior, o muestra desventajas con respecto a la clásica intervención de sinuslift a través de un abordaje por la pared lateral de la maxila? Si analizamos los resultados obtenidos con los de la elevación del seno maxilar con un bloque óseo, los de ésta última, muestran en los controles radiográficos una grán reabsorción del tejido óseo sobrante, el cual se encuentra a tal distancia de los implantes, que no recibe ningún estímulo de cargas funcionales (Wiltinger 1993). Dado a que el seno maxilar es una cámara neumática, es lógico suponer que cuando ésta se ve reducida después de un sinuslift con masiva cantidad de material de relleno, la disminución del volumen del antro provoque un aumento de la presión interna, lo cual podría originar una determinada reabsorción sobre el hueso transplantado, que no esté sujeto a estímulos funcionales.

$\mathrm{Al}$ observar los resultados obtenidos con un sinuslift local, cabe dejar abierta la pregunta, de que si es 
absolutamente indispensable el abordaje por la pared lateral de la maxila en los casos de defectos menores.

En el caso de un sinuslift con sustitutos óseos - que no sufren un proceso de completa reabsorción - éstos permanecen en el hueso como un material inerte a lo largo de muchos años y podrían comportarse como un cuerpo extraño susceptible a posibles infecciones, incluso muchos años después de la intervención.

En los casos de defectos mayores es indispensable el uso de la clásica técnica de sinuslift descrita por numerosos autores.

Nuestra experiencia clínica de hace más de 6 años muestra claramente que el sinuslift local con hueso autólogo para la corrección de defectos péqueños, cumple perfectamente con el objetivo de lograr un lecho implantario adecuado conformado por hueso vital. Los controles radiográficos muestran delgadas cúpulas óseas emergentes en el seno maxilar, que circunscriben la porción apical de los implantes dentales. Esta estructura de hueso vivo es totalmente suficiente para absorber las exigencias funcionales generadas por las fuerzas masticatorias. Esta observación se basa en los óptimos resultados clínicos obtenidos con esta técnica a lo largo de seis años.

\section{BIBLIOGRAFÍA:}

1. Abbot, LC, Schottstaedt, ER, Saunders, JB, Bost, FC: The evaluation of cortical and cancellous bone and grafting material. J Bone JT Surg: 29, 381- 386 ( 1947 )

2. Albrektsson, T: The healing of autologous bone grafts after varying degrees of surgical trauma. J Bone Joint Surg: 62B, Nr. 3, 1980

3. Bassett, CAL.: Clinical implications of cellfunction in bone grafting. Clin Orthopäd.: 87, 49- 59 ( 1972 )

4. Benzing U, Gall, H, Weber, $\mathrm{H}$ : Biomechanical aspects of two implant- prothetic concepts for edentulous maxillae. Int J Oral Maxillofac Impl: 13, 253. 262 ( 1996 )

5. Benzing, U, Pröbster, L, Weber, H, Gall, H: Die implantologisch- prothetische Versorgung des zahnlosen Oberkiefers- biomechanische Analyse vs. klinischer Befund. Zahnärztl Z Implantol: 12, 35- 42 ( 1996 )

6. Betts, NJ und Miloro, M: Modification of the sinus lift procedure for septa in the maxillary antrum. J Oral Maxillofac Surg.: 52, 332- 333 ( 1994 )

7. Boyne, JP, James, RA: Grafting of the maxillary sinus floor with autogenous marrow and bone. J Oral Surg.: $38,613-616$ ( 1980$)$

8. Burchardt, H: Biology of bone transplantation. Orthop Clin North Amer: 18, 187- 196 (1987)

9. Catone, GA, Reimer, BC, Mc Neir, D, Ray, R: Tibial autogenous cancellous bone as an alternative donor- site in maxillofacial surgery: A preliminary report. J Oral Maxillofac Surg: 50, 1258- 1263 ( 1992 )

10. Desjardins, RP: Prothesis design for osseointegrated implants in the edentulous maxilla. Int J Oral Maxillofac Impl: 7, 311-320 ( 1992 )

11. Haas, R, Donath, K, Födinger, M, Watzek, G: Bovine hydroxyapatite for maxillary sinus grafting. Comparative histomorphometric findings in sheep. Clin Oral Impl Res: 9, 107- 116 (1998)

12. Hirsch, JM und Ericsson I: Maxillary sinus augmentation using mandibular bone grafts and simultaneous installation of implants. A surgical technique. Clin Oral Impl Res: 2, 91- 96 (1991)

13. Jensen, OT, Shulman, LB, Block, MS, Iacono, VJ: Report of the sinus consensus conference of 1996. Int J Oral Maxillofac Impl: 13 ( 1998 ) special suppl. 11- 32

14. Kent, JN und Block MS: Simultaneous maxillary sinus floor bone grafting and placement of hydroxylapatitecoated implants: J Oral Maxillofac Surg: 47, 238- 242 ( 1989 )

15. Krekeler, G, Schilli, W, ten Bruggenkate, CM, Kniha, H, Schenk, R. Gahlert, M: Sinusbodenaugmentation- eine zuverlässige Methode zur Verbesserung der Implantatintegration? Z Zahnärztl Implantol.: 14, 198207 ( 1998 )

16. Kübler, N, Urist, MR, Reuther, J: Subperiostale Knochenneubildung durch Knochenmatrixproteine ( BMP ). Dtsch. Z Mund- Kiefer- Gesichtschir. 16, 265- 271 ( 1992 )

17. Nyström, E, Kahnberg, $\mathrm{KH}$, Albrektsson, T: Treatment of the severely resorbed maxilla with bone graft and titanium implants. Histologic review of the autopsy specimens. Int J Oral Maxillofac Impl: 8, 167- 172 ( 1993 )

18. Ray, RD und Sabet, TY: Bone grafts: Cellular survival versus induction. J Bone Joint Surg: 45A, Nr.2 ( 1963 )

19. Rudzki, M, Burri, C, Hutschenreuter, P: Der Ein- und Umbau von autologer Spongiosa und Kompakta im ersatzschwachen Knochenlager. Langenbeck's Arch Chir, Suppl Chir Forum: 263- 266 ( 1976 ) 
20. Schilli, W, Krekeler, G, Spielberg, M: Spongiosatransplantate zur Verbesserung des Implantatlagers im Oberkiefer: ( in Vorbereitung )

21. Schweiberer, L, Eitel, F, Betz, A: Spongiosatransplantationen. Chirurg: 53, 195-200 (1982)

22. Small, SA, Zinner, ID, Panno, FV, Shapiro, HJ, Stein, JI: Augmenting the maxillary sinus for implants: Report of 27 patients. Int J Oral Maxillofac Impl: 8, 523- 528 ( 1993 )

23. Spielberg, M: Spongiosatransplantatezur Verbesserung des Implantatlagers im Oberkiefer. Med. Diss. 1999

24. Spiessl, B: Grundsätzliches zur Knochentransplantation. Fortschr. Kiefer- Gesichtschir: 20, 14- 17 ( 1976 )

25. Solar, P, Aro, G, Ulm, C, Bernhart, T: Die Auswirkungen des Zahnverlustes auf die Anatomie der Maxilla. Schweiz Mschr. Zahnmed: 108, 871- 875 ( 1998 )

26. Summers, RB: The osteotomie technique: Part 3- less invasive methods of elevating thze sinus floor. Compend Contin Educ Dent: 6, 698- 708 ( 1994 )
27. Tatum H.: Lectures presented at the Alabama study group ( 1977 )

28. Ten Bruggenkate, CM, van den Bergh JPA.: Maxillary sinus floor elevation: a valuable prosthetic procedure. Periodontol 2000, 17, 176- 182 ( 1998 )

29. Ten Bruggenkate,CM, Kraaijenhagen, HA, van der Kwast, WA, Krekeler, G, Oosterbeek, HS: Autogenous maxillary bone grafts in conjunction with placement of ITI endosseous implants. Int J Oral Maxillofac Surg: 21, 81- 84 ( 1992 )

30. Urist, MR, Solberman, BF, Buring, K, Dubuc, FL, Rosenberg, JM.: The bone induction principle. Clin Orthop. 53, 243- 271 ( 1967 )

31. van den Bergh, JPA, ten Bruggenkate CM, Krekeler, G.: Sinus lift procedures with autogenous bone from the iliac crest. Int J Oral Maxillofac Impl.: in press

32. Wiltinger, $\mathrm{K}$ : Orale Rehabilitation durch implantatfixierte autologe Beckenspantransplantate- eine Resorptionsanalyse mit der Panoramaschichtaufnahme. Med. Diss. Freiburg, 1993 